\title{
Mce3R Stress-Resistance Pathway Is Vulnerable to Small-Molecule Targeting That Improves Tuberculosis Drug Activities
}

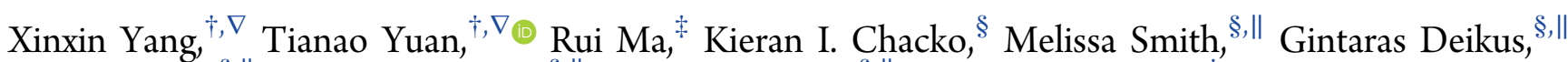
Robert Sebra, ${ }^{\S, \|}$ Andrew Kasarskis, ${ }^{\S, \|}$ Harm van Bakel, ${ }^{\S, \|}$ Scott G. Franzblau, ${ }^{\ddagger}$ and Nicole S. Sampson $*, \dagger, \perp, \#$ (0)

${ }^{\dagger}$ Department of Chemistry, Stony Brook University, 100 John S. Toll Drive, Stony Brook, New York 11794-3400, United States

${ }^{\ddagger}$ Institute for Tuberculosis Research, University of Illinois at Chicago, 833 South Wood Street, 425 PHARM, Chicago, Illinois 60612-7231, United States

${ }^{\S}$ Department of Genetics and Genomic Sciences, Icahn School of Medicine at Mount Sinai, One Gustave L. Levy Place, Box 1498, New York City, New York 10029, United States

"Icahn Institute for Genomics and Multiscale Biology, Icahn School of Medicine at Mount Sinai, One Gustave L. Levy Place, Box 1498, New York City, New York, 10029-6574, United States

${ }^{\perp}$ Institute of Chemical Biology and Drug Discovery, Stony Brook University, 100 John S. Toll Drive, Stony Brook, New York 11794-3400, United States

${ }^{\#}$ Stellenbosch Institute for Advanced Study (STIAS), Wallenberg Research Centre at Stellenbosch University, 10 Marais Street, Stellenbosch 7600, South Africa

Supporting Information

ABSTRACT: One-third of the world's population carries Mycobacterium tuberculosis $(\mathrm{Mtb})$, the infectious agent that causes tuberculosis (TB), and every $17 \mathrm{~s}$ someone dies of TB. After infection, $M t b$ can live dormant for decades in a granuloma structure arising from the host immune response, and cholesterol is important for this persistence of $M t b$. Current treatments require long-duration drug regimens with many associated toxicities, which are compounded by the high doses required. We phenotypically screened 35 6-azasteroid analogues against $M t b$ and found that, at low micromolar concentrations, a subset of the analogues sensitized $M t b$ to multiple TB drugs. Two analogues were selected for further study to characterize the bactericidal activity of bedaquiline and isoniazid under normoxic and low-oxygen conditions. These two 6-azasteroids showed strong synergy with bedaquiline (fractional inhibitory concentration index $=0.21$, bedaquiline minimal inhibitory concentration $=16 \mathrm{nM}$ at $1 \mu \mathrm{M}$ 6-azasteroid). The rate at which

Mtb

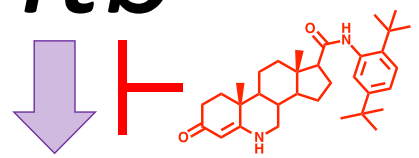

Stress Resistance spontaneous resistance to one of the 6 -azasteroids arose in the presence of bedaquiline was approximately $10^{-9}$, and the 6 azasteroid-resistant mutants retained their isoniazid and bedaquiline sensitivity. Genes in the cholesterol-regulated Mce3R regulon were required for 6-azasteroid activity, whereas genes in the cholesterol catabolism pathway were not. Expression of a subset of Mce3R genes was down-regulated upon 6-azasteroid treatment. The Mce3R regulon is implicated in stress resistance and is absent in saprophytic mycobacteria. This regulon encodes a cholesterol-regulated stress-resistance pathway that we conclude is important for pathogenesis and contributes to drug tolerance, and this pathway is vulnerable to small-molecule targeting in live mycobacteria.

KEYWORDS: cholesterol, codrug, low oxygen

$\mathrm{C}$ holesterol metabolism plays an important role in the persistence, virulence, and intracellular survival of Mycobacterium tuberculosis $(\mathrm{M} t b) .{ }^{1-5} \mathrm{M} t \mathrm{~b}$ is able to survive and replicate inside macrophages ${ }^{6}$ by utilizing host-derived nutrients, including cholesterol. ${ }^{1-3,7} \mathrm{M} t \mathrm{~b}$ catabolism of cholesterol provides a source of acetyl-coenzyme A (CoA), pyruvate, and propionyl-CoA, which can be utilized for energy production and as lipid precursors. ${ }^{8}$ Catabolism proceeds through $\beta$-oxidation of the side chain and oxidative cleavage of the sterol rings. ${ }^{9}$ Comparison of transcriptional profiles of $M t b$ cultured with and without cholesterol identified over 200 genes that are regulated by cholesterol. ${ }^{2}$ At least 52 cholesterolregulated genes are clustered within the $M t b$ genome and encode the enzymes needed for catabolism. ${ }^{2,8}$ Two TetR family regulators, KstR1 and KstR2, control transcription of the majority of these catabolism genes ${ }^{10,11}$ and are derepressed by $\mathrm{CoA}$ metabolites of the catabolism pathway. ${ }^{12,13}$

Received: March 9, 2019

Published: April 23, 2019 


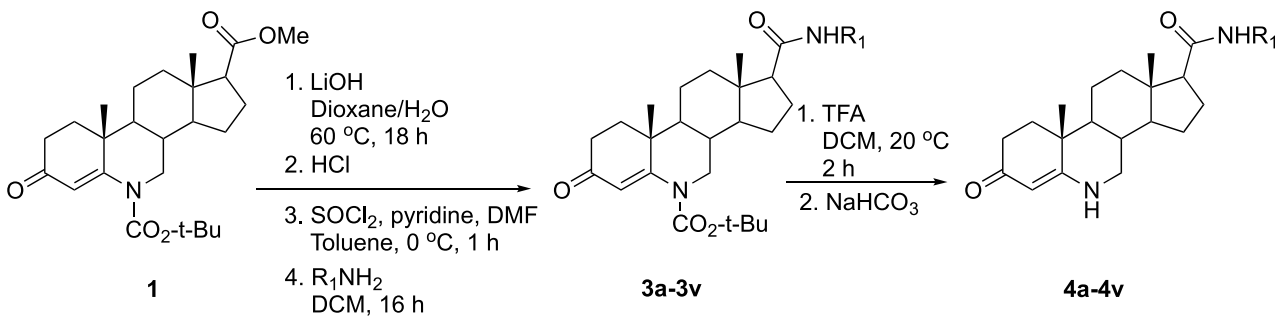

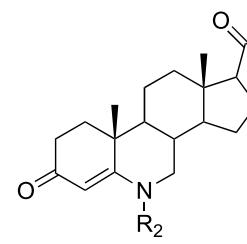

5a: $R_{2}=$ methyl

6a, 6b: $\mathrm{R}_{2}=n$-propyl

7a: $\mathrm{R}_{2}=n$-hexyl

a: -(2,5-di-t-butyl)phenyl
b: -(2-t-butyl, 5-trifluoromethyl)phenyl
c: -(2,5-di-trifluoromethyl)phenyl
d: -(3,5-di-t-butyl)phenyl
e: -(2-t-butyl)phenyl
f: -(3-t-butyl)phenyl
g: -(4-t-butyl)phenyl
h: -(2-trifluoromethoxy, 4-fluoro)phenyl
i: -(2-trifluoromethoxy, 4-chloro)phenyl
j: -(2-trifluoromethoxy, 4-bromo)phenyl
k: -(2-trifluoromethoxy, 4-iodo)phenyl
l: -(2-trifluoromethoxy, 3-trifluoromethyl)phenyl
m: benzyl

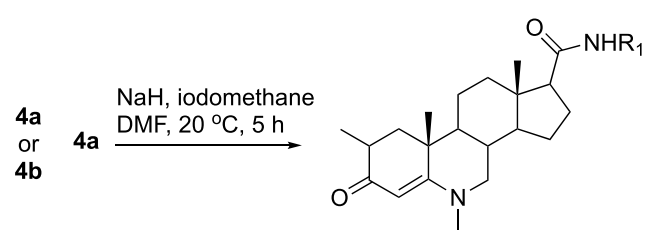

$8 a$

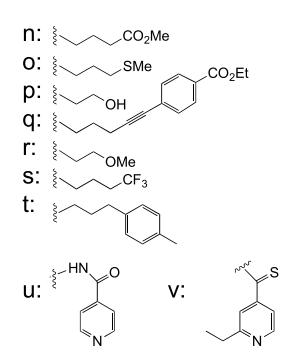

Figure 1. Structures and synthesis of 6-azasteroids. Key intermediate $\mathbf{1}$ was prepared as described in the literature ${ }^{16-18}$ and subjected to further elaboration as shown.

Owing to the large number of potential targets in the $M t b$ cholesterol metabolism pathway, the protein target that would be the most vulnerable to inhibition is not clear. ${ }^{14}$ Therefore, we undertook whole-cell phenotypic screening to identify inhibitors of $M t b$ growth. We reasoned that use of a steroid scaffold would bias the screen to target cholesterol metabolism. We further sought a scaffold with pharmacokinetic properties that would be advantageous for future in vivo experimentation.

For this purpose, we chose the 6-azasteroid scaffold (Figure $1)$. The 6-azasteroids were developed by Glaxo-Wellcome as part of a $5 \alpha$-reductase inhibitor program for treatment of benign prostatic hyperplasia, but they were subsequently abandoned in favor of 4-azasteroids. ${ }^{15-18}$ Several 6-azasteroids were found to be orally bioavailable in rats, dogs, or both and to have low in vivo toxicity. ${ }^{16}$ Because of the pharmacokinetic properties of 6-azasteroids and their structural similarity to cholesterol, we chose to screen them as possible inhibitors of cholesterol metabolism in $M t b$.

Previously, we demonstrated that 6-azasteroids with a large, hydrophobic $\mathrm{R}_{1}$ side chain and an unsubstituted N6 atom (e.g., 4a, Figure 1) are competitive inhibitors of $3 \beta$-hydroxysteroid dehydrogenase. ${ }^{19}$ However, because this enzyme is not essential for $M t b$ survival in the mouse or guinea pig models of infection, its relevance as a drug target was questionable. ${ }^{20}$ We reasoned that other enzymes in the $M t b$ cholesterol metabolism pathway might also be susceptible to inhibition by compounds with the 6-azasteroid scaffold. In the present study, we identified several 6-azasteroids with antimycobacterial activity that improve the activity of existing anti-TB drugs, and we established a relationship between activity and side- chain structure. By investigating the mechanism of action and the target of two of the active 6-azasteroids in $M t b$, we identified a connection between stress resistance and cholesterol-regulated genes that reside outside the cholesterol catabolic pathway. The inhibitors described herein offer a strategy for combating innate drug tolerance in $M t b$ and highlight the complex role of cholesterol-regulated genes in $M t b$ infection.

\section{RESULTS}

6-Azasteroids Were Prepared from Intermediate 1. Following a previously established synthetic route, ${ }^{15-18}$ we prepared a library of 6-azasteroids from key intermediate 1 (Figure 1), which was prepared on a $500 \mathrm{~g}$ scale. Briefly, hydrolysis of the methyl ester group of $\mathbf{1}$ followed by activation of the resulting carboxylic acid and substitution reactions with various primary amines provided amides 3 with more than 20 different substituents at $\mathrm{R}_{1}$. Subsequent deprotection of the ring nitrogen provided compounds $4 \mathbf{a}-\mathbf{4 v}$. Alkylation of $4 \mathbf{a}$ or $\mathbf{4 b}$ at N6 provided compounds $5 \mathbf{a}-7 \mathbf{a}$ and $\mathbf{6 b}$. Treatment of $4 \mathbf{a}$ with an excess of sodium hydride and iodomethane yielded $8 \mathrm{a}$, which has a methyl group both on the ring nitrogen and at $\mathrm{C} 2$. All compounds were purified by column chromatography before testing. Yields from intermediate 1 ranged from $60 \%$ to $90 \%$.

6-Azasteroids Inhibit Mtb Growth in Combination with Isoniazid. We initially screened the synthesized 6azasteroids (Figure 1) to determine their minimal inhibitory concentrations (MICs) in a Mtb growth assay. As a carbon source, we used cholesterol solubilized in tyloxapol detergent 


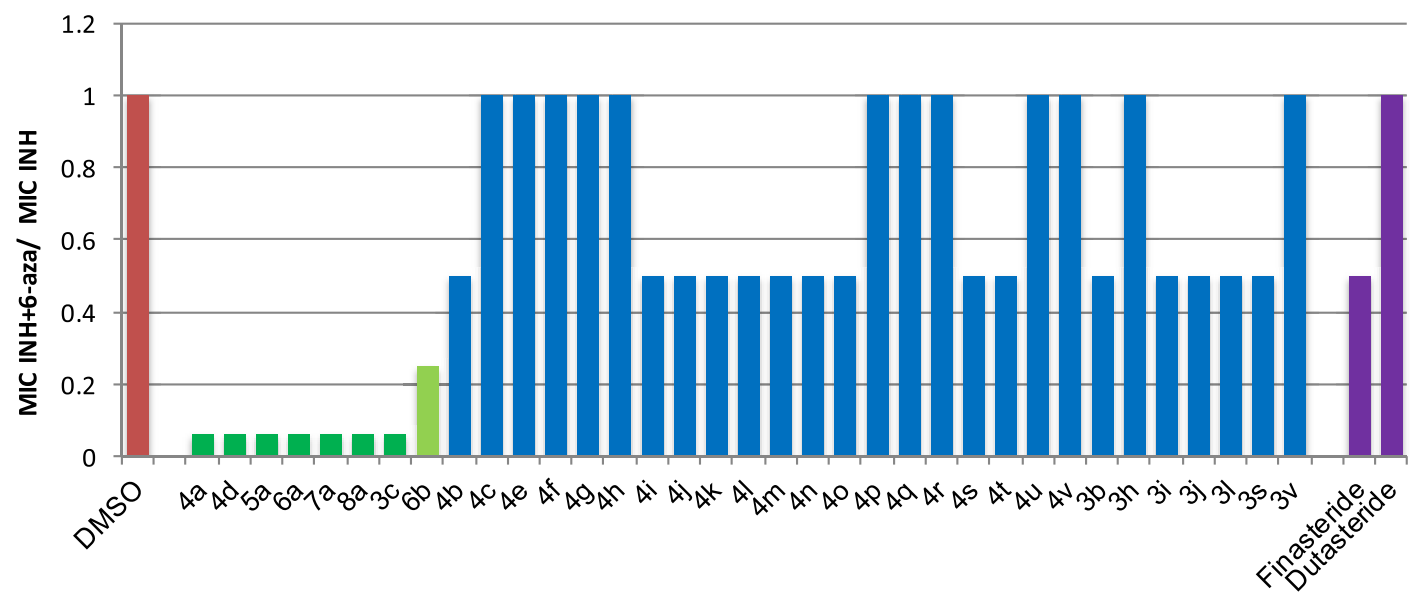

Figure 2. 6-Azasteroids improve the efficacy of INH. CDC1551 Mtb in 7H9 medium with cholesterol as a carbon source was incubated with $20 \mu \mathrm{M}$ 6-azasteroid, finasteride, dutasteride, or DMSO control and varying concentrations of INH (2-fold dilutions) for 14 days at $37{ }^{\circ} \mathrm{C}$. The INH concentration at which no growth occurred was recorded as the MIC. Results are shown as the ratio of the INH MIC in the presence of azasteroid or DMSO to the MIC of INH alone $(0.2-0.4 \mu \mathrm{M})$. A ratio of $0.5-1$ is considered to indicate no change in the INH MIC. The data shown are representative of at least two experiments.

micelles to ensure that we could detect activity against the cholesterol catabolism pathway. The 6-azasteroid concentrations were varied from 0.15 to $40 \mu \mathrm{M}$. We were unable to obtain accurate MICs, but we estimated the values to exceed $40 \mu \mathrm{M}$ for the compounds that showed at least some activity.

Despite the lack of MICs for most of the 6-azasteroids, we recognized that they might show synergistic activity when combined with isoniazid (INH), a frontline TB drug. Therefore, we screened for inhibition of $M t b$ growth at a fixed concentration of 6-azasteroid $(20 \mu \mathrm{M})$ while varying the INH concentration. The potentiation potency was recorded as a fold change of the INH MIC. Of the 35 6-azasteroids tested in combination with $\mathrm{INH}$, seven $(\mathbf{4 a}, \mathbf{4 d}, \mathbf{5 a}-\mathbf{8} \mathbf{a}$, and $3 \mathrm{c}$ ) improved the INH MIC at least 16-fold (Figure 2). In addition, compound $\mathbf{6 b}$ showed moderate potentiation with a 4-fold decrease in the INH MIC. We also tested two 4azasteroids, finasteride and dutasteride, which inhibit human $5 \alpha$-reductase and are FDA-approved for treatment of benign prostatic hyperplasia. Neither of the 4-azasteroids showed inhibitory activity, either alone or in combination with INH.

Clear Structure-Activity Relationship Was Observed for the 6-Azasteroids. Among the compounds with $\mathrm{R}_{2}=\mathrm{H}$ (4), an aniline side chain at $\mathrm{R}_{1}$ was required. Compounds with side chains derived from aliphatic amines (4n, 4o, 4p, 4r, 4s) or aliphatic amines linked to aromatic groups $(\mathbf{4 m}, \mathbf{4 q}, \mathbf{4 t})$ were inactive. Furthermore, compounds with aniline side chains bearing a single substituent $(\mathbf{4 e}, \mathbf{4 f}, \mathbf{4 g})$, compounds with aniline side chains bearing polar substituents $(\mathbf{4 b}, \mathbf{4 c}, \mathbf{4 h}$, $4 \mathbf{i}, 4 \mathbf{j}, 4 \mathbf{k}, 4 \mathbf{l})$, and compounds with pyridyl-based side chains $(4 \mathbf{u}$ and $4 \mathbf{v})$ were inactive. Only $4 \mathbf{a}$ and $4 \mathbf{d}$, the (2,5-di-tbutyl)phenyl and the (3,5-di-t-butyl)phenyl compounds, improved INH activity. The activity of parent compound 4 a was retained upon installation of an alkyl $R_{2}$ substituent on the ring nitrogen (5a, 6a, 7a). Interestingly, moderate potentiation was observed upon conversion of the inactive 2-t-butyl-5trifluoromethylaniline-derived compound $\mathbf{4 b}$ to $N$-propyl derivative $6 \mathbf{b}$. Likewise, compound $3 \mathbf{c}$, which has a $t$ butyloxycarbamate-protected ring nitrogen, was active, whereas the corresponding unprotected compound (4c) was not. Thus, derivatization of the aza ring nitrogen was well tolerated and, in some cases, could convert inactive compounds into potentiators of INH activity.

6-Azasteroid Activity Is Not Specific for Cholesterol Catabolism. Next, we assessed the specificity of the 6azasteroid scaffold for cholesterol catabolism. We found that when glycerol was used as the carbon source, the seven active 6-azasteroids retained their ability to improve the efficacy of INH. As a negative control, we tested compound $\mathbf{4 g}$, which was inactive with cholesterol as the carbon source, and found it remained inactive in glycerol (Figure S1). Thus, the activity of 6-azasteroids was not carbon-source specific.

Two of the active compounds, $4 \mathbf{a}$ and $\mathbf{6 a}$, were selected for further study. Their effect on the rates of CDC1551 Mtb growth was monitored by optical density (OD). As expected from our initial MIC screen, $10 \mu \mathrm{M} 4 \mathbf{a}$ or $6 \mathrm{a}$ did not inhibit the growth of $M t b$ on glycerol as a carbon source over the course of 15 days (Figure 3A).

6-Azasteroids Improve the Activity of Other TB Drugs and Drug Candidates. Compounds $4 \mathrm{a}$ and $6 \mathrm{a}$ were tested as potentiators of the following additional TB drugs and drug candidates: rifampin, pretomanid, bedaquiline (BDQ), clofazimine, pyrazinamide, moxifloxacin, linezolid, and ethionamide. We found that these two 6-azasteroids improved the activity of at least five of the TB drugs in vitro: rifampin, pretomanid, $\mathrm{BDQ}$ pyrazinamide, and ethionamide (Tables 1 and S1A). The 6-azasteroids did not appear to improve the activity of clofazimine, linezolid, or moxifloxacin. BDQ in addition to INH, was selected for further study because it is used for the treatment of multidrug-resistant $M t b$ infection.

6-Azasteroids Show Synergism with INH or BDQ. Using the $\mathrm{H} 37 \mathrm{Rv}(m l u x)$ strain, we carried out a checkerboard growth-inhibition assay at various $4 \mathbf{a}$ or $\mathbf{6 a}$ and INH or BDQ concentrations. As expected, neither 10 nor $20 \mu \mathrm{M}$ 4a inhibited the growth of $\mathrm{H} 37 \mathrm{Rv}(m l u x)$ (Figure 3B). A subMIC concentration of INH $(0.032 \mu \mathrm{M})$ also failed to inhibit growth. However, when $M t b$ was treated simultaneously with $20 \mu \mathrm{M} 4 \mathrm{a}$ and $0.032 \mu \mathrm{M}$ INH, growth was inhibited. Similarly, at a low concentration $(4 \mu \mathrm{M}), \mathrm{BDQ}$ alone inhibited growth by approximately $50 \%$. Importantly, when BDQ was used in combination with $\mathbf{4 a}$, complete inhibition was observed. Likewise, combinations of $6 \mathrm{a}$ and $0.032 \mu \mathrm{M}$ INH or $4 \mu \mathrm{M}$ 
A

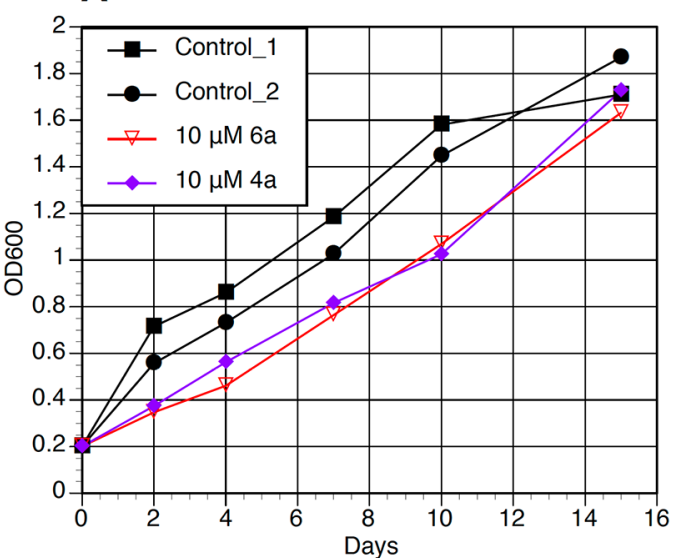

C

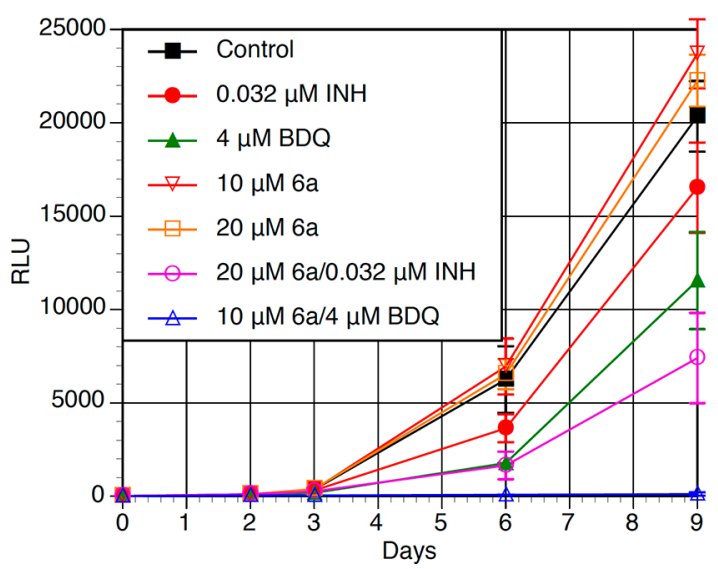

B

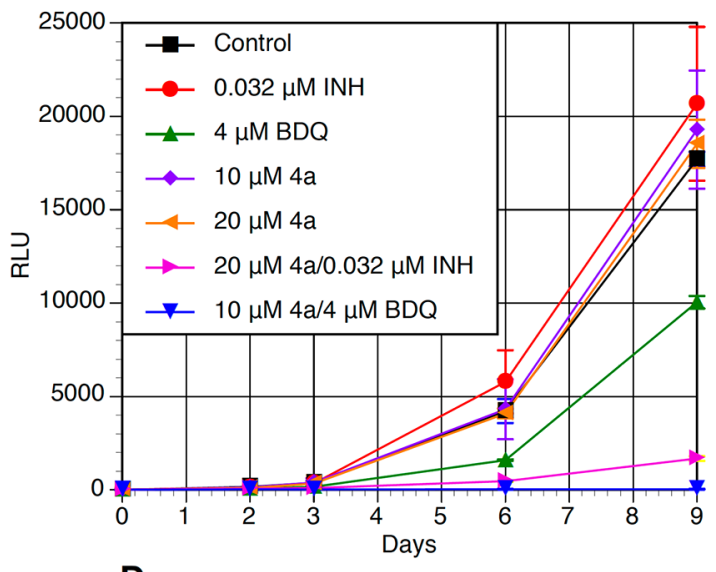

D

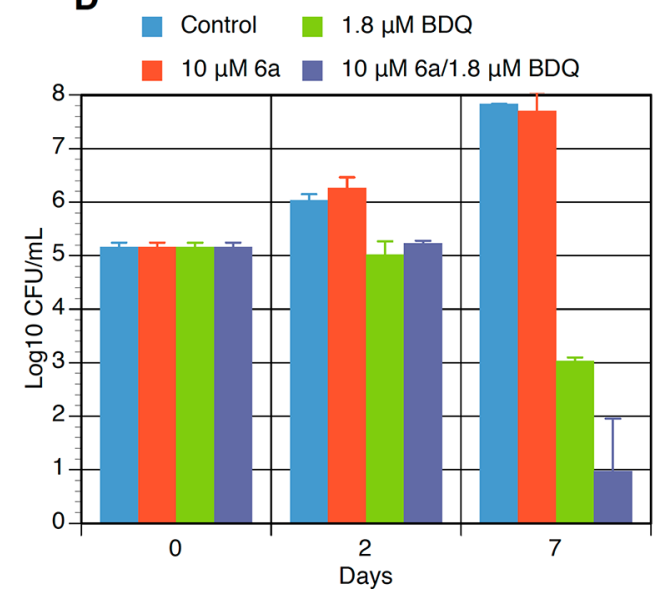

Figure 3. Azasteroids 4a and 6a inhibit $M t b$ growth and are bactericidal in combination with INH or BDQ. (A) CDC1551 Mtb was cultured in $7 \mathrm{H} 9$ medium with glycerol as a carbon source and was diluted to an OD $(600 \mathrm{~nm})$ of 0.2 . These cultures were incubated with $10 \mu \mathrm{M} 4 \mathrm{a}$ or $6 \mathrm{a}$ or with DMSO as a control (two replicates), and the growth of $M t b$ was monitored by OD $(600 \mathrm{~nm})$ for 15 days. Data are representative of at least two experiments. (B) $\mathrm{H} 37 \mathrm{Rv}(m l u x) M t b$ was cultured in $7 \mathrm{H} 9 /$ glycerol medium and diluted to approximately 5-10 RLU per well. These cultures were incubated with INH, BDQ and/or $\mathbf{4 a}$ at the indicated concentrations or with DMSO as a control, and the growth of $M t b$ was monitored by autoluminescence for 9 days. (C) $\mathrm{H} 37 \mathrm{Rv}(m l u x) M t b$ was cultured in $7 \mathrm{H} 9 /$ glycerol medium and diluted to approximately 5-10 RLU per well. These cultures were incubated with $\mathrm{INH}, \mathrm{BDQ}$ and/or $\mathbf{6 a}$ at the indicated concentrations or with DMSO as a control, and the growth of Mtb was monitored by autoluminescence for 9 days. (D) CDC1551 Mtb was cultured in 7H9/glycerol medium and diluted to an OD (600 nm) of approximately 0.002 . These cultures were incubated with BDQ and/or 6a at the indicated concentrations or with DMSO as a control. After 2 or 7 days, the cultures were diluted, and the CFUs were determined by serial dilution onto agar plates. Error bars in panels B-D indicate SDs $(n=2)$. The limit of detection is $10 \mathrm{CFU} / \mathrm{mL}$.

BDQ resulted in complete inhibition (Figure 3C). Growth readings at day 9 were used to prepare an isobolographic plot for INH and 6-azasteroid (Figure S2). Although an accurate 6azasteroid MIC could not be determined from the plots, the combinations of $\mathbf{4 a}$ or $\mathbf{6 a}$ and INH were clearly synergistic.

6-Azasteroids Improve Bactericidal Activity. Combining 6a with $\mathrm{BDQ}(1.8 \mu \mathrm{M})$ improved the bactericidal activity of BDQ. Specifically, the combination of $10 \mu \mathrm{M}$ 6a and BDQ resulted in a $2 \log _{10}$ CFU improvement in bacterial kill at day 7 of treatment. However, the rate of bacterial kill by BDQ was not increased, as evidence by the 2-day time points (Figures $3 \mathrm{D}$ and S3A). The combination of $\mathbf{4 a}$ and INH was also bactericidal (Figure S3B).

6-Azasteroids Are More Potent under Low-Oxygen Conditions than under Normoxic Conditions. We also conducted a checkerboard low-oxygen recovery assay (LORA) of $\mathrm{H} 37 \operatorname{Rv}(m l u x)$ growth inhibition by $\mathbf{4 a}$ or $\mathbf{6 a}$ and INH or $\mathrm{BDQ}$ at various concentrations (Figure 4). Both $\mathbf{4 a}$ and $\mathbf{6 a}$ were active in the LORA, showing MICs of 11 and $13 \mu \mathrm{M}$, respectively. Although INH was not active under low-oxygen conditions $(\mathrm{MIC} \approx 400 \mu \mathrm{M})$, treatment with INH plus 4a or 6a reduced the MIC at least 2-fold (Figure 4A). The LORA fractional inhibitory concentration (FIC) indices for INH/4a and $\mathrm{INH} / 6 \mathrm{a}$ were 0.75 and 0.69 , respectively. BDQ had an MIC of $160 \mathrm{nM}$ in the LORA. Compound 4a or $6 \mathbf{a}$ improved BDQ activity in the LORA (Figure 4B). At $4.4 \mu \mathrm{M}, 4 \mathrm{a}$ reduced the BDQ MIC approximately 50 -fold (to $3 \mathrm{nM}$ ), and 6 a reduced the BDQ MIC to $23 \mathrm{nM}$. The FIC index for both $\mathrm{BDQ} / 4 \mathrm{a}$ and $\mathrm{BDQ} / \mathbf{6 a}$ was 0.21 , indicating strong synergy.

6-Azasteroids Improve the Bactericidal Activity of BDQ under Low-Oxygen Conditions. The bactericidal activities of $4 \mathbf{a}$ and $6 \mathbf{a}$ were determined under low-oxygen conditions. The minimum bactericidal concentration of $\mathbf{4 a}$ was $80 \mu \mathrm{M}$ and that of $6 \mathrm{a}$ was higher than $80 \mu \mathrm{M}$ ( $80 \%$ kill). To assess the bactericidal activity of combinations of 6 -azasteroids and BDQ we performed a time-kill assay with $10 \mu \mathrm{M} 4 \mathbf{a}$ or $6 \mathbf{a}$ in combination with $\mathrm{BDQ}$ at concentrations below the minimum bactericidal concentration (Figure 4C). At day 10 
Table 1. 6-Azasteroids 4a and 6a Improve the Efficacy of Multiple TB Drugs ${ }^{a}$

\begin{tabular}{|c|c|c|c|c|}
\hline \multirow[b]{2}{*}{ Drug } & \multirow[b]{2}{*}{ Drug target } & \multicolumn{3}{|c|}{ Drug MIC } \\
\hline & & $\begin{array}{c}\text { Alone }^{b} \\
(\mu \mathrm{M})\end{array}$ & $\begin{array}{c}\text { With } \\
\mathbf{4 a}\end{array}$ & $\begin{array}{c}\text { With } \\
\mathbf{6 a}\end{array}$ \\
\hline $\mathrm{INH}$ & cell-wall synthesis & 0.4 & & \\
\hline Rifampin ${ }^{c}$ & RNA polymerase & 0.025 & & \\
\hline Pretomanid & cell-wall synthesis & 0.05 & & \\
\hline $\mathrm{BDQ}$ & ATP synthase & 0.4 & & \\
\hline Clofazimine $^{d}$ & unknown & 25 & & \\
\hline Pyrazinamide $^{c}$ & unknown & 20,000 & & \\
\hline Moxifloxacin & DNA synthesis & 0.4 & & \\
\hline Linezolid & protein synthesis & 0.8 & & \\
\hline Ethionamide $^{c}$ & cell-wall synthesis & 6.25 & & \\
\hline
\end{tabular}

${ }^{a} \mathrm{CDC} 1551 \mathrm{Mtb}$ or $\mathrm{H} 37 \mathrm{Rv}(m l u x) \mathrm{Mtb}$ in $7 \mathrm{H} 9$ medium with glycerol as a carbon source was incubated at $37{ }^{\circ} \mathrm{C}$ with $20 \mu \mathrm{M} 4 \mathrm{a}$ or 6 a or with DMSO control and one of the listed drugs (2-fold dilution) at various concentrations for 14 days (CDC1551) or 6 days $(\mathrm{H} 37 \mathrm{Rv}(m l u x))$. The drug concentration at which no growth occurred was recorded as the drug MIC. The ratio of the drug MIC in the presence of azasteroid to the MIC of the drug alone was determined. Ratios of $0.0625-0.125$ are indicated by green shading and are considered to reflect potentiation. Ratios of $0.5-1$ are indicated by red shading and are considered to reflect no change in MIC. Data are representative of at least two independent biological replicate experiments, which were performed in technical triplicate. MIC values are listed in Table S1A. ${ }^{b}$ Values in this column are MICs for CDC1551 Mtb except for clofazimine. ${ }^{c}$ Experiment performed only with CDC1551 Mtb. ${ }^{d}$ Experiment performed only with $\mathrm{H} 37 \mathrm{Rv}(m l u x) M t b$.

of treatment, the combination of $10 \mu \mathrm{M} 4 \mathrm{a}$ and $0.15 \mu \mathrm{M}$ BDQ resulted in a $3.2 \log _{10} \mathrm{CFU}$ reduction in bacterial kill relative to that in a no-drug control group. In addition, this same combination $(10 \mu \mathrm{M}$ 4a plus $0.15 \mu \mathrm{M}$ BDQ) resulted in a 1.4 $\log _{10}$ CFU reduction in bacterial kill at day 10 relative to that in the BDQ-only group at a slightly higher BDQ concentration $(0.25 \mu \mathrm{M})$; that is, $10 \mu \mathrm{M}$ 4a plus $0.15 \mu \mathrm{M}$ BDQ was more potent than $1-0.25 \mu \mathrm{M}$ BDQ alone (Figure 4C).

6-Azasteroids Retain Potentiation Activity in Cholesterol Catabolism Mutants. Because 6-azasteroids are cholesterol analogues, we determined whether the cholesterol catabolism pathway was required for azasteroid activity. For this purpose, we tested the activity of 6-azasteroids in combination with $\mathrm{INH}$ in mutant $M t b$ strains with disrupted cholesterol catabolism genes. Specifically, we selected strains with mutations in fadA5, chsE4 (fadE26), fadE31, and fadE33 (the transcription of which is repressed by the two main transcriptional regulators of cholesterol catabolism, KstR1 and

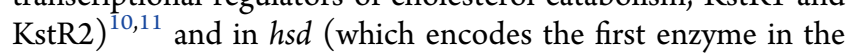
pathway). ${ }^{21}$ KstR1 regulates the transcription of genes encoding side-chain- and A/B-ring-degrading enzymes, whereas KstR2 regulates the transcription of genes encoding $C / D$ ring-degrading enzymes. These two regulators are derepressed by CoA metabolites in the pathway. ${ }^{12,13}$ We found that none of these five genes were required for $\mathbf{4 a}$ to improve INH activity against $M t b$ grown with either cholesterol or glycerol as the carbon source (Tables 2 and S1B).

Mce3R Regulon Is Required for Potentiation of INH by 6-Azasteroids. Previously, we discovered that the Mce3R regulon encodes FadE17-FadE18, an unusual heterotetrameric acyl-CoA dehydrogenase that is associated with cholesterol metabolism. ${ }^{22}$ Moreover, Mce3R regulates the mel2 operon, which is implicated in $M t b$ persistence in macrophages ${ }^{23}$ and in resistance to oxidative stress ${ }^{24}$ that is associated with lipid metabolism. $^{25,26}$ The regulon is derepressed upon treatment with cholesterol, most likely by a cholesterol metabolite, ${ }^{2}$ and expression of the regulon is up-regulated during hypoxia and in the stationary phase. ${ }^{27}$ We found that azasteroid $4 a$ no longer improved INH activity when tested against Mtb Mce3R regulon mutants $\mathrm{fadE} 18, \mathrm{melF}$, and $\mathrm{melH}$ (Table 2), and this loss of activity was independent of carbon source.

The cholesterol catabolism pathway regulated by KstR1 and KstR2 is found in both saprophytic and pathogenic mycobacteria. ${ }^{28}$ In contrast, the Mce3R regulon is conserved in M. marinum and $M t b$ but not in other pathogens (e.g., M. avium) or in saprophytic mycobacteria (e.g., M. smegmatis). In results consistent with our mutant potentiation data, we found that 6-azasteroid $\mathbf{4 a}$ did not improve INH or BDQ activity when tested against $M$. smegmatis or M. avium grown with glycerol as a carbon source (Table 2). However, inhibition of $M$. marinum growth by BDQ and INH was increased by addition of $\mathbf{4 a}$.

Spontaneous Resistance to 6a Is Mce3R Independent. We examined the frequency with which spontaneous resistance to one of the azasteroids arose (Table 3). Specifically, resistant mutants were raised against 6 a alone and in combination with BDQ. The reported frequency of in vitro resistance to $20 \mu \mathrm{M}$ BDQ ranges from $9 \times 10^{-9}$ to $5 \times$ $10^{-7}$ mutations per cell division, and mutations arise predominately in the atpE gene. ${ }^{29}$ We found similar frequencies of BDQ resistance in this study. The frequencies of resistant mutant formation upon treatment with $\mathbf{6 a}$ in combination with BDQ were comparable to the frequencies of BDQ resistance. Treatment with $\mathbf{6 a}$ alone resulted in an 

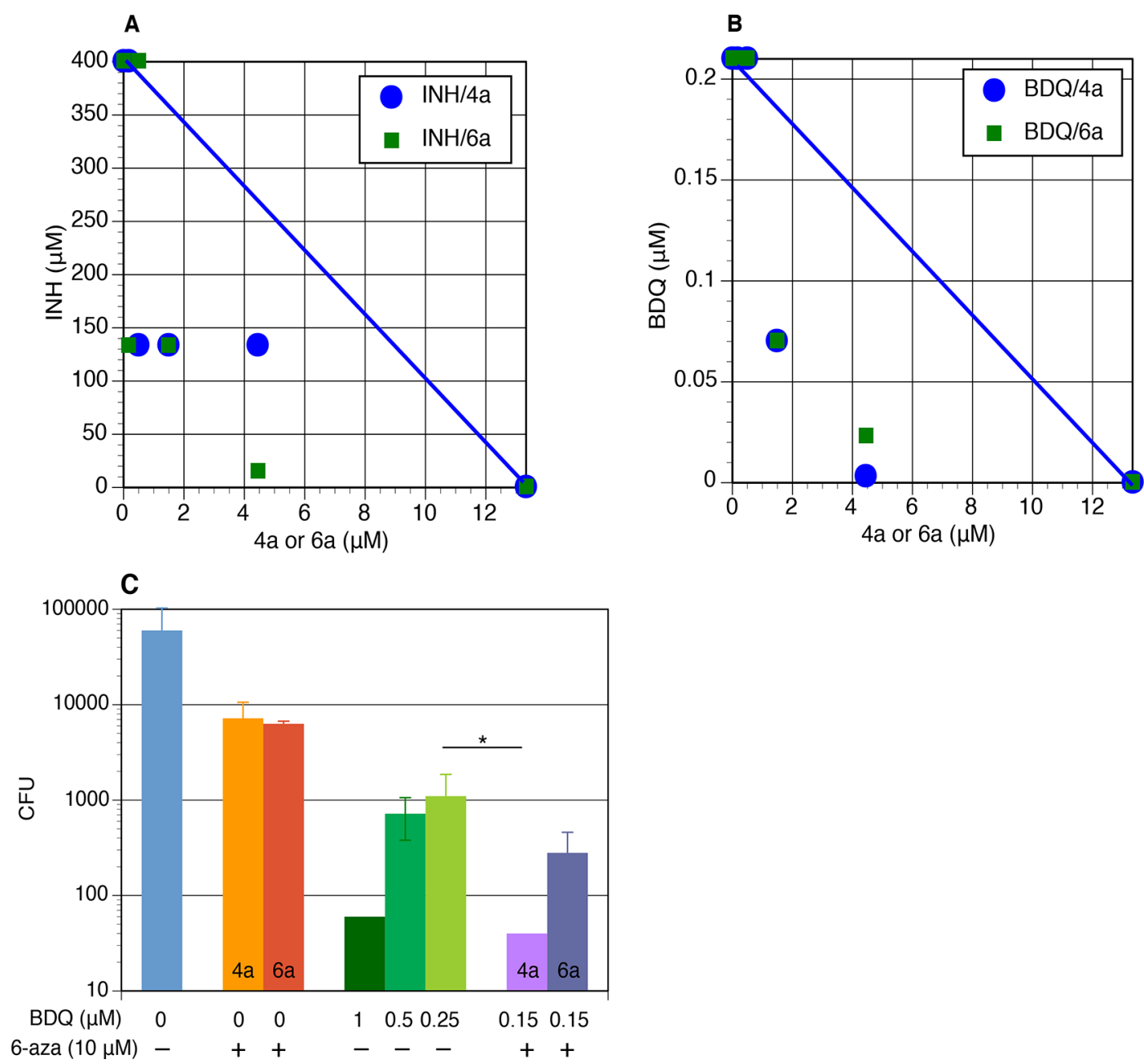

Figure 4. 6-Azasteroids and INH or BDQ interact under low-oxygen conditions. Isobolographic analysis of codrug LORA MIC in H37Rv(mlux) Mtb: (A) INH and $4 \mathbf{a}$ or $6 \mathbf{a}$ and (B) BDQ and $4 a$ or $6 \mathbf{a}$. The lines connecting $400 \mu \mathrm{M}$ INH or $0.21 \mu \mathrm{M}$ BDQ and $13 \mu \mathrm{M} 4 \mathbf{a}$ or $6 \mathbf{a}$ denote lines of additivity. $\mathrm{H} 37 \mathrm{Rv}($ mlux $) M t b$ was cultured and diluted to approximately 5-10 RLU per well. These cultures were incubated with INH or BDQ and $4 \mathbf{a}$ or $6 \mathbf{a}$ at a checkerboard of concentrations (3-fold dilutions) or with DMSO as a control under hypoxic conditions for 10 days. The RLU values for $\mathrm{H} 37 \mathrm{Rv}(\mathrm{mlux}) \mathrm{Mtb}$ after $28 \mathrm{~h}$ of normoxic recovery were recorded. The drug concentrations in wells with at least $90 \%$ inhibition of growth relative to that in the no-drug control are plotted. Plotted values are averages $(n=3)$. (C) H37Rv $(m l u x) M t b$ was cultured at approximately $1 \times 10^{5}$ $\mathrm{CFU} / \mathrm{mL}$. These cultures were incubated with BDQ $4 \mathrm{a}(10 \mu \mathrm{M})$, or $6 \mathrm{a}(10 \mu \mathrm{M})$, alone or in combination, at the indicated concentrations under hypoxic conditions for 10 days. The cultures were diluted, and CFUs were determined by serial dilution onto agar plates. Plotted values are averages with SDs $(n=3) ; *_{p}<0.05$. The limit of detection is $10 \mathrm{CFU} / \mathrm{mL}$.

approximately 5-10-fold higher frequency of resistance. All the resistant mutants that formed upon treatment of $6 \mathbf{a}$ alone or in combination with BDQ had significant alterations in colony morphology. The wild-type colonies were thick, rough, irregular, and yellow, whereas the mutant colonies were thin, small, round, and almost transparent (Figure S4). Twenty mutants were selected, and six of these grew in liquid culture. The mutant colonies unable to grow in liquid culture were restreaked on agar plates, and one more mutant grew. All the resistant mutants grew slowly in liquid culture or on agar plates. The 6a, BDQ and INH MICs against these seven mutants were determined (Figure S1C). Against three of the mutants (ASR1, ASR4, and ASR5), the MIC of $6 \mathbf{a}$ increased more than 4-fold with respect to the MIC against WTCDC1551, whereas a 2-4-fold increase was observed for the remainder of the mutants. The INH and BDQMICs against all the 6a-selected mutants were unchanged (1-2-fold increase) compared to their MICs against WT-CDC1551.
DNA from six of the resistant mutants was sequenced. Only three mutants (ASR1, ASR2, and ASR3) produced high-quality data; the DNA from the other three mutants was highly fragmented. Twenty-nine nonsynonymous single nucleotide polymorphisms (SNPs), occurring in 25 genes, were identified and confirmed by at least 10 Illumina reads (Figure S5). Of the 25 genes, 6 belong to the PE/PPE family and 3 encode enzymes involved in PDIM biosynthesis.

Because mutant ASR2 showed no significant increase in the 6a MIC, we focused on analyzing mutants ASR1 and ASR3, in which we identified, respectively, 21 and 11 nonsynonymous SNPs, with 3 SNPs that were identical in both mutants. A stop gain occurred at $\mathrm{S} 154$ in $\mathrm{Rv} 2940 c$, which encodes a mycocerosic acid synthase involved in PDIM biosynthesis. In addition, we identified a frameshift insertion at P188 in Rv3467, a nonessential gene, and a recombination of PPE19. No Mce3R gene mutations were identified in the resistant mutants. 
Table 2. Mce3R Regulon Is Required for Azasteroid 4a Activity $^{a}$

\begin{tabular}{|c|c|c|c|}
\hline Regulon & Mutated Mtb gene ${ }^{b}$ & $\mathrm{Chol}^{\mathrm{d}}$ & Glyc $^{d}$ \\
\hline \\
\hline \multicolumn{4}{|c|}{ None (WT-H37Rv) } \\
\hline \multicolumn{4}{|c|}{$h s d$} \\
\hline \multirow{2}{*}{ KstR1 } & fadA5 & & \\
\hline & chsE4 (fadE26) & & \\
\hline \multirow{2}{*}{ KstR2 } & fadE31 & & \\
\hline & fadE33 & & \\
\hline \multirow{5}{*}{ Mce3R } & echA13 & & \\
\hline & fadE18 & & \\
\hline & melF & & \\
\hline & melH & & \\
\hline & fadE18::pfadE18 & & \\
\hline Mce3R & Species $^{\mathrm{C}}$ & $\mathrm{INH}^{\mathrm{d}}$ & $\mathrm{BDQ}^{\mathrm{d}}$ \\
\hline \multirow{2}{*}{$\begin{array}{c}\text { not } \\
\text { conserved }\end{array}$} & M. avium & & \\
\hline & M. smegmatis & & \\
\hline \multirow[t]{2}{*}{ conserved } & M. marinum & & \\
\hline & Mtb & & \\
\hline
\end{tabular}

${ }^{a}$ The data shown are representative of at least two independent biological replicates and were performed in technical triplicate. ${ }^{b}$ With cholesterol or glycerol as a carbon source, the indicated strain of $M t b$ in $7 \mathrm{H} 9$ medium was incubated with $20 \mu \mathrm{M} 4 \mathrm{a}$ or DMSO control and INH at various concentrations (2-fold dilutions) for 14 days at $37^{\circ} \mathrm{C}$. ${ }^{c}$ With glycerol as a carbon source, the indicated species of mycobacteria in $7 \mathrm{H} 9$ medium was incubated with $20 \mu \mathrm{M} 4 \mathbf{a}$ or DMSO control and INH or BDQ at various concentrations (2-fold dilutions) for $4-7$ days at $37{ }^{\circ} \mathrm{C}$. ${ }^{d}$ The drug concentration at which no growth occurred was recorded as the drug MIC. MIC values are shown in Table S1B. The ratio of the drug MIC in the presence of $\mathbf{4 a}$ to the MIC of INH or BDQ alone was determined. Ratios of 0.06250.125 are indicated with green shading and reflect potentiation. Ratios of $>0.125$ and $\leq 0.5$ are indicated with orange shading and reflect low potentiation due to low activity of INH against M. marinum. Ratios $>0.5$ are indicated with red shading and reflect no change in MIC.

Table 3. Frequencies of in Vitro Spontaneous Resistance to $6 \mathrm{a}$ and $\mathrm{BDQ}^{a}$

\begin{tabular}{lllc} 
& \multicolumn{3}{c}{ frequency of resistance $^{b}$} \\
\cline { 2 - 4 } & $\mathrm{BDQ}(20 \mu \mathrm{M})$ & $\mathrm{BDQ}(10 \mu \mathrm{M})$ & $\mathrm{BDQ}(0 \mu \mathrm{M})$ \\
$\mathbf{6 a}(400 \mu \mathrm{M})$ & $7.8 \times 10^{-8}$ & $\mathrm{ND}$ & $1.1 \times 10^{-7}$ \\
$\mathbf{6 a}(200 \mu \mathrm{M})$ & $\mathrm{ND}$ & $2 \times 10^{-7}$ & $3.6 \times 10^{-6}$ \\
$\mathbf{6 a}(0 \mu \mathrm{M})$ & $5.5 \times 10^{-9}$ & $3.4 \times 10^{-7}$ &
\end{tabular}

${ }^{a} \mathrm{CDC} 1551 \mathrm{Mtb}$ was plated on $7 \mathrm{H} 11$ medium supplemented with $10 \%$ OADC containing the indicated concentration of $\operatorname{drug}(\mathrm{s})$. Resistant mutants were counted after 3-4 weeks. ND = not detected. ${ }^{b}$ Mutations per cell division.

As for individual nonsynonymous mutations, we determined that ASR1 carried a nonsynonymous SNP in guaB3 (Rv3410c), which is an essential gene annotated as an inosine- $5^{\prime}$ monophosphate dehydrogenase (Figure S5). However, GuaB3 does not perform this dehydrogenase enzymatic function. ${ }^{30}$ The guaB3 gene resides in a three-gene operon $R v 3409 c-g u a B 3-g u a B 2$, and $R v 3409 c$ is required for bacterial survival and growth in macrophages. ${ }^{31}$ We also identified frameshift deletions in $R v 0678, R v 2552 c$, and $R v 3267$ from ASR1. These genes are involved in the regulation of a cell efflux system, aromatic amino acid synthesis, and cell-wall synthesis, respectively. A frameshift deletion was also identified in $R v 0204 c$ from ASR3. The disruptions in genes involved in mycobacterial cell-wall biosynthesis are consistent with the phenotypic changes in colony morphology that we observed.

6-Azasteroids Suppress the Transcription of Mtb Stress-Response Genes Including the Mce3R Regulon. RNA-seq gene expression profiles of the wild-type CDC1551 $M t b$ and the resistant mutants ASR1 and ASR2 were generated after $6 \mathrm{~h}$ of exposure to $4 \mathrm{a}$ or $\mathbf{6 a}$. Upon treatment of the wildtype with $\mathbf{4 a}$ or $\mathbf{6 a}$, genes involved in lipid metabolism, cell-wall synthesis and cell processes, $\mathrm{PE} / \mathrm{PPE}$, and information pathways (TubercuList functional classes) were generally down-regulated ( $>2$-fold). The global expression profiles for 4a and 6a treatment were like the profile for BDQ treatment, with $>80 \%$ of the genes that were down-regulated by BDQ (>1.5-fold) also being down-regulated (>1.5-fold) by $4 \mathrm{a}^{32} \mathrm{In}$ the absence of any of the test compounds, resistant mutants ASR1 and ASR2 had a common set of 49 up-regulated (>2fold) genes, including stress-response genes regulated by DosR, PhoP/R, MprA, Crp, and WhiB3. ${ }^{33}$

In addition to the observed general response to drug treatment, six sets of genes that appeared to be specific to the 6-azasteroid mechanism of action were up- or down-regulated by treatment of wild-type CDC1551 Mtb with $4 \mathbf{a}$ or $\mathbf{6 a}$ (Figures 5 and S6). The magnitude of differential expression of these specific genes in response to treatment with $4 \mathbf{a}$ or 6 a was much lower in ASR1 than in the wild-type, a result that is consistent with the increased drug MIC.

In the wild-type CDC1551 Mtb, the KstR1 and KstR2 regulon genes that encode cholesterol catabolism enzymes were either up-regulated or unaffected (Figure 5). In contrast, KstR1 genes not directly related to cholesterol catabolism were greatly down-regulated (up to 25-fold, not shown). Additionally, KstR1-regulated genes in the mce4 operon, which encodes the cholesterol transport system, were down-regulated by $\mathbf{4 a}$ or 6a. Genes in the mcelR operon, which is associated with mycolic acid transport, and in the mell operon, which encodes putative membrane protein and transglutaminases thought to be important for infection, ${ }^{23}$ were greatly down-regulated ( $>5$ fold). In the wild-type, the Mce3R-regulated echA13-fadE17fadE18 operon was down-regulated by treatment with $\mathbf{4 a}$ or $\mathbf{6 a}$, whereas the other two Mce3R-regulated operons were unaffected. In addition, guaB2, which is in the $R v 3409 c$ guaB3-guaB2 operon, was up-regulated by $\mathbf{4 a}$ or $\mathbf{6 a}$ (Table S4). Gene expression of representative genes from Mce3R, KstR1, and KstR2 regulons and mell operon in Mtb CDC1551 exposed to $\mathbf{4 a}$ was confirmed by qRT-PCR (Figure S6).

\section{DISCUSSION}

We tested 37 azasteroids in MIC assays and identified a set of eight 6-azasteroids that clearly sensitized $M t b$ to existing TB drugs (Figure 2). We observed a clear structure-activity relationship, indicating that the compounds acted on a specific target or targets. The TB agents that exhibited synergy with these 6-azasteroids utilize a wide array of killing mechanisms, disrupting processes ranging from cell-wall biosynthesis to ATP biosynthesis (Table 1 ).

We found that genes involved in cholesterol catabolism were not required for the activity of 6-azasteroid 4a (Table 2), despite our previous work demonstrating that 6-azasteroids, including $4 a$, inhibit the first enzyme in the catabolic pathway, $3 \beta$-hydroxysteroid dehydrogenase $(h s d),{ }^{19}$ and a body of evidence indicating that cholesterol catabolism is important for 


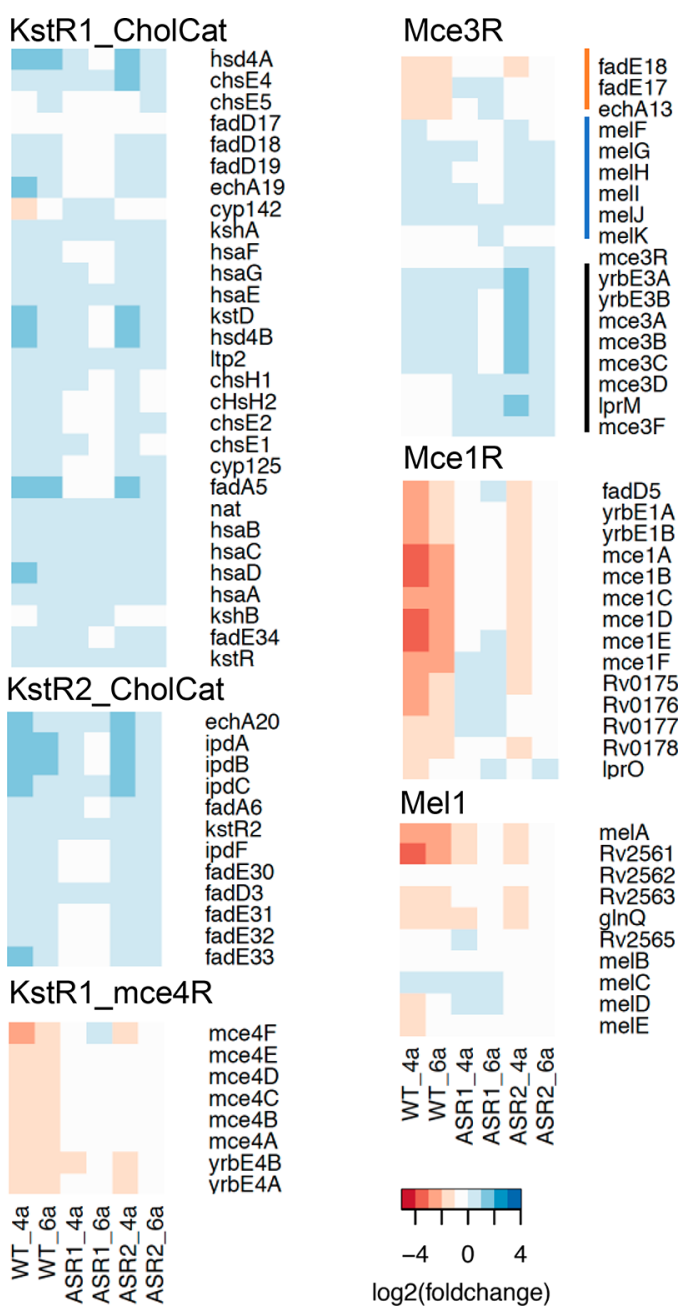

Figure 5. Differentially expressed transcripts as analyzed by RNA-seq are visualized in heatmaps. The transcriptional profiles of $M t b$ strains CDC1551 (WT), ASR1, and ASR2 exposed for $6 \mathrm{~h}$ to $4 \mathrm{a}(30 \mu \mathrm{M})$ or 6a $(30 \mu \mathrm{M})$ were compared with the profile of the corresponding untreated group. Gene names are indicated to the right of the heatmap, and strains and treatment conditions are shown on the bottom. The color scales represent $\log _{2}$-fold changes in gene expression in treated groups relative to expression in untreated groups; each colored cell represents the mean of biological triplicates. Red, blue, and black lines denote the echA13-fadE17-fadE18, mel2, and mce3 operons, respectively.

$M t b$ persistence and survival in a mouse model of infection. ${ }^{1,2}$ Moreover, the 6-azasteroids were active against $M t b$ grown on a sugar carbon source, glycerol, as well as against $M t b$ grown on a cholesterol carbon source (Figure 2). Importantly, 6azasteroids $4 \mathbf{a}$ and $6 \mathbf{a}$ were active under low-oxygen growth conditions. Taken together, the evidence suggests that 6azasteroids act on a target that contributes to drug tolerance regardless of carbon source or oxygen level.

Transcriptional, ${ }^{2}$ phenotypic, ${ }^{34}$ and biochemical profiling ${ }^{22}$ have identified genes outside the $M t b$ cholesterol catabolism gene cluster that are regulated by cholesterol, that are important for growth on cholesterol in vitro, or that have cholesterol-specific structural motifs. Several of these genes are found within a TetR-like transcriptional regulon controlled by the Mce3R repressor. ${ }^{26,27}$ Transposon disruption of $m c e 3 R$ significantly inhibits growth of $M t b$ on cholesterol. ${ }^{34}$ However, the genes within the Mce3R regulon are not required for catabolism of cholesterol, ${ }^{8,9}$ suggesting that these genes have an alternate role in $M t b$ survival. Therefore, we investigated the importance of four genes in the Mce3R regulon ( $\mathrm{FadE18}$, echA13, $m e l F$, and $m e l H)$ in 6-azasteroid activity. Intriguingly, $\mathrm{fadE} 18, \mathrm{melF}$, and $\mathrm{melH}$ were required for 6-azasteroid potentiation of INH activity. Although echA13, annotated to encode an enoyl-CoA hydratase, was not required, the $M t b$ genome encodes many other enoyl-CoA hydratases that might compensate for disruption of this gene.

The precise biochemical functions of the proteins encoded in the Mce3R regulon have yet to be established. However, bioinformatics and phenotypic assays allow for tentative assignment of their function. The fadE17, fadE18, and mel2 genes are important contributors to $M t b$ resistance to various cellular stresses. The entire Mce3R locus is present in M. marinum and provides resistance to reactive oxygen species and reactive nitrogen species. ${ }^{24}$ Significantly, the Mce3R regulon is absent in saprophytic mycobacteria, ${ }^{28}$ which suggests that the primary role of the regulon is mediating host-derived stresses, such as those encountered by $M t b$ in activated macrophages. Consistent with this observation, the mel2 operon is required for persistence and dissemination of $M t b$ infection in mice. ${ }^{35}$

The fadE17 and fadE18 genes encode an acyl-CoA dehydrogenase with an unusual $\alpha_{2} \beta_{2}$ heterotetrameric that is characteristic of acyl-CoA dehydrogenases that oxidize cholesterol-derived substrates. $^{22}$ The melF and melH genes reside in a single operon $(R v 1936-R v 1941)$ of the mel2 locus, which encodes homologues of the Lux luminescence system. This system catalyzes formation of a fatty acid aldehyde by means of an ATP-dependent process.

The mel2 operon is thought to provide resistance to oxidative stress, which is consistent with the idea that the operon encodes catalytic machinery to generate a fatty acid aldehyde that can remove oxidizing species from the cellular milieu. ${ }^{24}$ When $M t b$ production of ergothioneine, which is a redox couple in $M t b$, is disrupted, fadE18 is up-regulated. ${ }^{36}$ When $M t b$ is exposed to a lysosomal soluble fraction prepared from activated macrophages, both $\mathrm{fadE} 17$ and $\mathrm{fadE} 18$ are induced. ${ }^{37}$ In addition, a recent study has shown that cysteine in combination with INH or rifampin can enhance oxygen consumption by $M t b$, thereby leading to increased production of reactive oxygen species and sterilization of $M t b$ cultures. ${ }^{38}$ Upon addition of cysteine to INH-treated $M t b$ cultures, the transcription level of $f a d E 18$ increases nearly 4-fold. Treatment of $M t b$ with BDQ for $48-96 \mathrm{~h}$ results in up-regulation of mel2 genes, especially $m e l F$, which is up-regulated about 8 -fold. ${ }^{32}$ These responses indicate that the Mce3R regulon plays a critical role in the $M t b$ response to oxidative, host-induced, or drug-induced stress.

In contrast to treatment with $\mathrm{INH}$, rifampin, or $\mathrm{BDQ}$, treatment with 6-azasteroid $4 \mathrm{a}$ or $\mathbf{6 a}$ for $6 \mathrm{~h}$ resulted in 3- to 4fold down-regulation of the Mce3R-regulated echA13-fadE17$\mathrm{fadE} 18$ operon. Although the transcription levels of mel2 genes were unchanged or only marginally changed after $6 \mathrm{~h}$ of 6 azasteroid treatment, the response of the mel2 gene to $\mathrm{BDQ}$ treatment is likely to be indirect, given the long post-BDQ treatment time $(48-96 \mathrm{~h})$ at which up-regulation is observed. ${ }^{32}$ Together with our mutant experiment in which fadE 18 was required for 6 -azasteroid potentiation, the evidence supports a mechanism in which the 6-azasteroids suppress fadE18/Mce3R-dependent activation of a drug-induced stressresistance pathway. 
$M t b$ spontaneous resistant mutants that were raised against 6a showed a thinner, almost transparent cell-wall phenotype and were difficult to culture. Importantly, we found that Mce3R genes were not directly involved in spontaneous resistance to the 6-azasteroid. Among the genes where nonsynonymous mutations occurred in the resistant mutants, $\mathrm{PE} / \mathrm{PPE}$ genes were not investigated further as candidates for involvement in the azasteroid-resistance phenotype, because of their high variability in $M t b$. In addition, it is unlikely that genes involved in PDIM biosynthesis are directly involved in the azasteroid-resistance phenotype, because the loss of PDIM production is commonly observed during in vitro propagation of $M t b$ cultures. $^{39}$ The remainder of the mutations identified were in genes involved in mycobacterial cell-wall synthesis and efflux systems, which is consistent with a mechanism of resistance that decreases 6-azasteroid uptake, and simultaneously, the growth fitness of $M t b$ is reduced.

In addition to suppressing Mce3R genes, 6-azasteroids also suppressed the expression of genes in the DosR, ${ }^{40} \mathrm{PhoP} / \mathrm{R},{ }^{33}$ and SigB regulons ${ }^{41}$ and in the icll operon. ${ }^{42}$ All these genes are involved in $M t b$ stress resistance and the establishment of persistence. There is evidence that inhibitors of DosR genes also increase the activity of $\mathrm{INH}^{43}$ although the increase is not as dramatic as that observed for 6-azasteroids. This enhancement of INH activity by the 6-azasteroids indicates that they inhibit a network of $M t b$ stress resistance and that the disruption of this network leads to the potentiation of TB drugs.

Codrug sensitization is emerging as a useful strategy for treating TB, including multidrug-resistant TB. ${ }^{44-47}$ Variations on this strategy include targeting specific drug-activation pathways ${ }^{46}$ as well as more general drug-desensitization targets such as the DosRST regulon ${ }^{43}$ and thiol stress. ${ }^{47}$ Thus, these drug-sensitization strategies are a powerful tool for killing resilient and/or nonreplicating $M t b$.

In summary, our work further supports the idea that Mce3Rregulated genes are important for managing the $M t b$ cellular response to drug-induced stress (Figure 6). Moreover, our

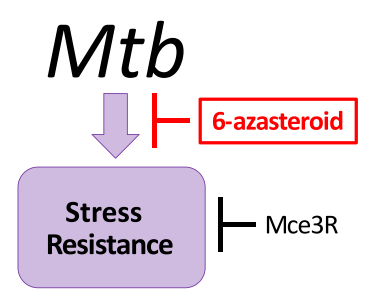

Figure 6. Efficacy of 6-azasteroids requires Mce3R-regulated genes. Genes in the Mce3R regulon are required for 6-azasteroid antimycobacterial activity. Cholesterol transcriptionally regulates the Mce3R genes, ${ }^{2}$ and this regulon is repressed by Mce3R, a tetR-like repressor protein.

findings suggest that $M t b$ depends on cholesterol or its metabolites for activation of stress resistance through the Mce3R regulon (Figure 6). Our discoveries that 6-azasteroid suppression of drug tolerance depends on Mce3R-regulated genes and occurs under low-oxygen conditions present an intriguing avenue for further development of codrugs that can improve the efficacy of existing TB drugs in vivo.

\section{MATERIALS AND METHODS}

Synthesis of 6-Azasteroid Precursor 1 and the Corresponding 17 $\beta$-Carboxylic Acid. 17 $\beta$-Carbomethoxy6-t-butoxycarbonyl-6-azaandrost-4-en-3-one (1) was synthesized as reported previously ${ }^{16-18}$ and then converted to $17 \beta$ carboxy-6-t-butoxycarbonyl-6-azaandrost-4-en-3-one as described in the literature. ${ }^{17}$ Both compounds were assessed to be greater than $95 \%$ pure by ${ }^{1} \mathrm{H}$ NMR spectroscopy.

General Procedure for Coupling Amines to the $17 \beta$ Carboxylic Acid and Subsequent Deprotection of the Ring Nitrogen. ${ }^{17} 17 \beta$-Carboxy-6-t-butoxycarbonyl-6-azaandrost-4-en-3-one $(30 \mathrm{mg})$ was suspended in $1 \mathrm{~mL}$ of toluene. One drop of DMF and $15 \mu \mathrm{L}$ of pyridine were added to the solution, which was then cooled in an ice bath, treated with 10 $\mu \mathrm{L}$ of thionyl chloride, and stirred for $1 \mathrm{~h}$. The solution was filtered, and the filtrate was concentrated. The resulting acid chloride residue was dissolved in DCM $(5 \mathrm{~mL})$ and treated with the desired amine to give amide 3 . Amide 3 was dissolved in DCM $(1 \mathrm{~mL})$ and treated with $2 \mathrm{~mL}$ of TFA at $20{ }^{\circ} \mathrm{C}$ to remove the $\mathrm{BOC}$ protecting group from the ring nitrogen. After $2 \mathrm{~h}$, the reaction mixture was poured into saturated $\mathrm{NaHCO}_{3}$ solution; the layers were separated, and the organic layer was washed with brine and dried over $\mathrm{Na}_{2} \mathrm{SO}_{4}$. Chromatography using $5 \%(\mathrm{v} / \mathrm{v}) \mathrm{MeOH}$ in $\mathrm{DCM}$ provided deprotected amide 4.

Procedure for N6 Alkylation of Deprotected Amides 4a and 4b. ${ }^{8,18}$ Amides 4a and 4b (30 mg) were dissolved separately in THF $(5 \mathrm{~mL})$ and treated with 1.2 equiv of $\mathrm{NaH}$. After stirring for $30 \mathrm{~min}$ at $20{ }^{\circ} \mathrm{C}$, the reaction mixture was treated with the desired iodoalkane ( 1 equiv) for a further 30 min. When the reaction was complete as judged by TLC (approximately $5 \mathrm{~h}$ ), $30 \mathrm{~mL}$ of EtOAc was added, and the resulting solution was washed with water and brine $(3 \times$ each) and dried over $\mathrm{Na}_{2} \mathrm{SO}_{4}$. Chromatography using $5 \%(\mathrm{v} / \mathrm{v})$ $\mathrm{MeOH}$ in DCM provided N6-alkylated amides 5a, 6a, 6b, and $7 \mathrm{a}$. For the synthesis of $\mathbf{8 a}$, amide $\mathbf{4 a}(30 \mathrm{mg})$ was dissolved in $\mathrm{DMF}$ and treated with 3 equiv of $\mathrm{NaH}$. After $30 \mathrm{~min}$ at $20^{\circ} \mathrm{C}$, 5 equiv of iodomethane was added into the reaction, followed by stirring at $20{ }^{\circ} \mathrm{C}$ for $2 \mathrm{~h}$ to give compound $8 \mathrm{a}$. Active azasteroids $4 \mathbf{a}, 5 \mathbf{5}, \mathbf{6 a}, \mathbf{8 a}$, and $3 \mathbf{c}$ were resynthesized for verification and were determined to be greater than $99 \%$ pure by LC-MS.

Bacterial Strains and Culture Conditions. Mutant and complemented strains used in this study and their sources are listed in Table S2. Mtb strains CDC1551, H37Rv, and $\mathrm{H} 37 \mathrm{Rv}(m l u x)$, also known as $\mathrm{H} 37 \mathrm{Rv}(\mathrm{pFCA}-\mathrm{luxABCDE})$, were used as wild-type strains for this study. $M t b$ strains were cultured at $37{ }^{\circ} \mathrm{C}$ either in Middlebrook $7 \mathrm{H} 9$ medium (broth) supplemented with $0.2 \%$ glycerol or $0.1 \mathrm{mM}$ cholesterol, $0.5 \% \mathrm{BSA}, 0.08 \% \mathrm{NaCl}$, and $0.05 \%$ (v/v) tyloxapol (7H9/glycerol or $7 \mathrm{H9} /$ cholesterol medium) or on $7 \mathrm{H} 11$ medium (agar) supplemented with $10 \%$ oleate-albumindextrose- $\mathrm{NaCl}$ (OADC), 0.5\% glycerol, and $0.05 \%$ Tween 80 .

Determination of MICs. MICs were determined by means of a broth microdilution assay. ${ }^{48}$ Briefly, cells were grown to mid log phase and then diluted 1000-fold in defined media. The cell suspension was added to a 96-well plate containing compound dilutions to obtain a final volume of $100 \mu \mathrm{L}$. Plates were incubated at $37{ }^{\circ} \mathrm{C}$ for 14 days, and MICs were determined as the lowest concentration that resulted in complete inhibition of growth by visual inspection or luminescence readouts ( $m l u x)$. For isobolograms, 5-fold serial 
dilutions of INH or BDQ were used so that the concentration range in a single plate was sufficient. If the $90 \%$ reduction in RLU could not be determined directly, a linear interpolation between two RLU values was used to determine the concentration at $90 \%$ inhibition.

LORA. ${ }^{49}$ A low-oxygen-adapted culture of $\mathrm{H} 37 \mathrm{Rv}(\operatorname{mlux})$ $M t b$ expressing a luciferase was used for the LORA. $\mathrm{H} 37 \mathrm{Rv}(\operatorname{mlux}) \mathrm{Mtb}$ stored at $-80{ }^{\circ} \mathrm{C}\left(1 \times 10^{5} \mathrm{CFU} / \mathrm{mL}\right)$ was thawed and exposed to 2 -fold or 3-fold serial dilutions of test compound diluted in $7 \mathrm{H} 12$ broth in black 96-well plates, which were incubated for 10 days at $37^{\circ} \mathrm{C}$ in an anaerobic jar under hypoxic conditions created with an Anoxomat system (MART Microbiology). Luminescence readouts were obtained after $28 \mathrm{~h}$ of normoxic recovery in $5 \% \mathrm{CO}_{2}$. To calculate the $\mathrm{MIC}$, the dose response curve was plotted as percentage growth and fitted to the Gompertz model. The MIC was defined as the lowest concentration inhibiting recovery of the luminescence signal by $90 \%$ relative to bacteria-only controls. FIC is defined as the ratio of the MIC of the inhibitor when used in combination to the MIC of the inhibitor alone. The FIC index is the sum of the FICs for the two drugs used. The minimum concentrations that worked in combination were used. The determination of drug MICs for rifampin, INH, linezolid, pretomanid, and BDQ were conducted as positive controls.

LORA Time-Kill Assay. The low-oxygen-adapted Mtb strain $\mathrm{H} 37 \mathrm{Rv}(m l u x)$ was cultured as described above for the LORA. Compounds $4 \mathbf{a}$ and $\mathbf{6 a}$ were tested at $10 \mu \mathrm{M}$ in combination with BDQ at $0.5,0.25,0.15,0.0625$, and $0.05 \mu \mathrm{M}$. At 0,7 , and 10 days, cultures were recovered in an aerobic environment $\left(5 \% \mathrm{CO}_{2}\right)$ for $28 \mathrm{~h}$ and then were serially diluted in $7 \mathrm{H} 9$ broth and plated on $7 \mathrm{H} 11 / \mathrm{OADC}$ agar plates. Drug concentration is diluted at least 300 -fold. Plates were incubated at $37{ }^{\circ} \mathrm{C}$, and CFUs were counted after 3-4 weeks. The limit of detection is $10 \mathrm{CFU} / \mathrm{mL}$. Statistical analysis was done using an unpaired Student's $t$-test (GraphPad Prism 4).

Aerobic Time-Kill Assay. Mtb was grown at $37{ }^{\circ} \mathrm{C}$ to mid $\log$ phase and then diluted in fresh medium to $5 \times 10^{5} \mathrm{CFU} /$ $\mathrm{mL}$. Test compounds were added at defined concentrations. Aliquots of cultures were withdrawn at specified time points, and either OD $(600 \mathrm{~nm})$ (CDC1551) or luminescence ( $m l u x)$ was recorded. At 0,2 , and 7 days, aliquots of cultures were serially diluted in $7 \mathrm{H} 9$ broth and plated on $7 \mathrm{H} 11$ /OADC agar plates. Drug concentration is diluted at least 300 -fold. Plates were incubated at $37{ }^{\circ} \mathrm{C}$, and CFUs were counted after 3-4 weeks. The limit of detection is $10 \mathrm{CFU} / \mathrm{mL}$.

Frequency of Resistance. $M t b$ mutants resistant to $\mathbf{6 a}$ were isolated by means of the procedure reported by Ioerger et al. ${ }^{50} \mathrm{H} 37 \mathrm{Rv} M t b$ bacteria were grown at $37{ }^{\circ} \mathrm{C}$ to mid log phase and then diluted in fresh Middlebrook $7 \mathrm{H} 9$ medium containing ADC-Tween 80 to $5 \times 10^{8} \mathrm{CFU} / \mathrm{mL}$. Middlebrook $7 \mathrm{H} 11 / \mathrm{OADC}$ agar plates with $6 \mathrm{a}$ at 200 or $400 \mu \mathrm{M}$ with or without 10 or $20 \mu \mathrm{M}$ BDQ were inoculated with $10^{8}, 10^{7}, 10^{6}$, and $10^{5} \mathrm{CFU} /$ plate, and the plates were incubated at $37^{\circ} \mathrm{C}$ for 3-4 weeks. Resistance was tested by measuring the MICs of 6a, BDQ, and INH. The frequency of the appearance of resistant mutants was calculated.

Whole Genome Sequencing. Mtb strains CDC1551, ASR1, ASR2, and ASR3 were grown to log phase, and their genomes were extracted with cetyltrimethylammonium bromide and lysozyme as described in the literature. ${ }^{51}$ Whole genome preparation, sequencing, assembly, and pairwise analysis were performed as previously described. ${ }^{52}$ Briefly,
DNA was sheared into 20000 bp fragments using Covaris Gtube spin columns and was end-repaired before being ligated to SMRTbell adapters (Pacific Biosciences). The resulting library was treated with an exonuclease cocktail to remove unligated DNA fragments and was size-selected on a Sage Science BluePippin system to obtain fragments of $\geq 7000 \mathrm{bp}$. The P5C3 sequencing enzyme and chemistry were used to sequence the resulting libraries on the Pacific Biosciences (PacBio) RS II platform. Resulting PacBio sequencing data were assembled using HGAP3 (ver. 2.2.0). For Illumina sequencing, genomic DNA $(1 \mu \mathrm{g})$ was sheared to achieve $\sim 200 \mathrm{bp}$ fragments using a Bioruptor Pico sonicator (Diagenode). Library preparation was performed using the end repair, A-tailing, and adaptor ligation NEBNext DNA library prep modules for Illumina from New England Biolabs, according to the manufacturer's protocol. The resulting libraries were sequenced on the Illumina HiSeq 2500 platform. Illumina reads were then mapped to the curated PacBio assemblies using samtools mpileup $^{53}$ to correct PacBio sequencing errors. Genome circularization, curation, and annotation were performed with a custom postassembly pipeline (https://github.com/ powerpak/pathogendb-pipeline). ${ }^{52}$ Finally, NUCmer (ver. $3.1)^{54}$ was used for aligning mutant genome strains to the PS00103 reference genome to identify genetic variants. Whole genome sequencing data are available in the NCBI BioProject database under accession number PRJNA482894.

RNA-seq Transcriptional Profiling and qRT-PCR. $M t b$ strains CDC1551, ASR1, and ASR2 were grown to OD 0.6 and treated with $30 \mu \mathrm{M} 4 \mathrm{a}$ or $6 \mathrm{a}$ or with vehicle control for $6 \mathrm{~h}$ in Middlebrook $7 \mathrm{H} 9$ medium supplemented with $0.2 \%$ glycerol, $0.5 \% \mathrm{BSA}, 0.08 \% \mathrm{NaCl}$, and $0.05 \%(\mathrm{v} / \mathrm{v})$ tyloxapol. Total RNA was extracted using TriZol, with chloroform back extraction and $70 \%$ ethanol precipitation. RNA was purified with an RNeasy kit (Qiagen) with DNase treatment. Total RNA was processed for ribosomal reduction library construction. Libraries were sequenced as single-end 75 bp reads on an Illumina NextSeq500 sequencer following the manufacturer's protocols (Cofactor Genomics, Inc.). The sequence reads were aligned to the CDC1551 Mtb complete genome (The National Center for Biotechnology Information Database) using STAR (https://github.com/alexdobin/ STAR). For each transcript or patch, the reads per kilobase million (RPKM) expression value was calculated for each sample. For each replicate group, the mean and coefficient of variation for each transcript or patch were calculated across the expression values for the samples in that group. These means were considered to be the expression values for the replicate group. $P$-values were calculated for comparisons between the means of each pair of replicate groups using a Welch's $t$-test corrected for false discovery rate by means of the BenjaminiHochberg procedure. For each comparison, differentially expressed genes were identified as genes with an average normalized count of $>100$, differential gene expression of $>2$ fold, and a $P$-value of $<0.05$. Three biological replicates were performed. RNA-seq data are available in the NCBI GEO database under accession number GSE118482. Total RNA was reverse-transcribed using PrimeScript RT Master Mix (TaKaRa Bio). The resulting cDNA was used for PCR amplification using iTaq Universal SYBR Green Supermix (Bio-Rad). Relative level of gene expression was calculated by the $\Delta \Delta \mathrm{Cq}$ method with $16 \mathrm{~s}$ rRNA as an internal control. Primers are listed in Table S3. 


\section{ASSOCIATED CONTENT}

\section{S Supporting Information}

The Supporting Information is available free of charge on the ACS Publications website at DOI: 10.1021/acsinfecdis.9b00099.

MICs; Mce3R regulon and azasteroid 4a activity; strains and plasmids used; primers used for qRT-PCR; 6azasteroids and efficacy of INH and how they interact; concentration dependence of $\mathbf{6 a}$ bactericidal activity with BDQ; bactericidal effect of $4 a$ and $\mathrm{INH}$; spontaneous resistant mutants to 6 a exhibiting altered colony morphology; genetic variants within mutant strains; confirmation of gene expression by qRT-PCR; spectral data for synthesized compounds (PDF) RNAseq transcriptional profiling (XLSX)

\section{AUTHOR INFORMATION}

\section{Corresponding Author}

*E-mail: nicole.sampson@stonybrook.edu.

\section{ORCID}

Tianao Yuan: 0000-0002-4700-8654

Scott G. Franzblau: 0000-0002-8698-0243

Nicole S. Sampson: 0000-0002-2835-7760

\section{Author Contributions}

${ }^{\nabla}$ X.Y. and T.Y. contributed equally to this work. X.Y., T.Y., and N.S.S. designed the research. X.Y., T.Y., R.M., and K.I.C. performed the research. M.S., G.D., R.S., and A.K. performed the whole genome sequencing. X.Y., T.Y., R.M., K.I.C., H.v.B., S.G.F., and N.S.S analyzed the data. X.Y., T.Y., and N.S.S. wrote the paper.

\section{Notes}

The authors declare the following competing financial interest(s): X.Y., T.Y., and N.S.S. are named inventors on patents and patent applications related to this Article.

\section{ACKNOWLEDGMENTS}

Research reported in this publication was supported by the National Heart, Lung, and Blood Institute and the National Institute of Allergy and Infectious Disease of the National Institutes of Health (award nos. U01HL127522, R01AI134054, and HHSN272201100009I) and BEI Resources. The content is solely the responsibility of the authors and does not necessarily represent the official views of the National Institutes of Health. Additional support was provided by the Center for Biotechnology, a New York State Center for Advanced Technology; Stony Brook University; Cold Spring Harbor Laboratory; Brookhaven National Laboratory; the Feinstein Institute for Medical Research; the New York State Department of Economic Development under Contract C14051. Shearson Editorial Services (Cornwall, NY, USA) provided English-language editing of the text of this paper.

\section{ABBREVIATIONS}

$\mathrm{BDQ}$ bedaquiline; CFU, colony forming unit; $\mathrm{DMF}$, dimethylformamide; DMSO, dimethyl sulfoxide; FIC, fractional inhibitory concentration; INH, isoniazid; LC-MS, liquid chromatography-mass spectrometry; LORA, low-oxygen recovery assay; MIC, minimum inhibitory concentration; Mtb, Mycobacterium tuberculosis; PDIM, phthiocerol dimycocerosates; PRKM, reads per kilobase million; qRT-PCR, quantitative reverse transcriptase real-time polymerase chain reaction; TB, tuberculosis; TLC, thin-layer chromatography; $\mathrm{THF}$, tetrahydrofuran; WT, wild-type

\section{REFERENCES}

(1) Pandey, A. K., and Sassetti, C. M. (2008) Mycobacterial persistence requires the utilization of host cholesterol. Proc. Natl. Acad. Sci. U. S. A. 105 (11), 4376-80.

(2) Nesbitt, N. M., Yang, X., Fontán, P., Kolesnikova, I., Smith, I., Sampson, N. S., and Dubnau, E. (2010) A thiolase of Mycobacterium tuberculosis is required for virulence and production of androstenedione and androstadienedione from cholesterol. Infect. Immun. 78 (1), $275-282$.

(3) Chang, J. C., Miner, M. D., Pandey, A. K., Gill, W. P., Harik, N. S., Sassetti, C. M., and Sherman, D. R. (2009) igr Genes and Mycobacterium tuberculosis cholesterol metabolism. J. Bacteriol. 191 (16), 5232-9.

(4) Ouellet, H., Guan, S., Johnston, J. B., Chow, E. D., Kells, P. M., Burlingame, A. L., Cox, J. S., Podust, L. M., and de Montellano, P. R. (2010) Mycobacterium tuberculosis CYP125A1, a steroid C27 monooxygenase that detoxifies intracellularly generated cholest-4-en3-one. Mol. Microbiol. 77 (3), 730-42.

(5) Peyron, P., Vaubourgeix, J., Poquet, Y., Levillain, F., Botanch, C., Bardou, F., Daffe, M., Emile, J. F., Marchou, B., Cardona, P. J., de Chastellier, C., and Altare, F. (2008) Foamy macrophages from tuberculous patients' granulomas constitute a nutrient-rich reservoir for M. tuberculosis persistence. PLoS Pathog. 4 (11), e1000204.

(6) Ulrichs, T., and Kaufmann, S. H. (2006) New insights into the function of granulomas in human tuberculosis. J. Pathol. 208 (2), 261-9.

(7) Yam, K. C., D’Angelo, I., Kalscheuer, R., Zhu, H., Wang, J.-X., Snieckus, V., Ly, L. H., Converse, P. J., Jacobs, W. R., Jr., Strynadka, N., and Eltis, L. D. (2009) Studies of a ring-cleaving dioxygenase illuminate the role of cholesterol metabolism in the pathogenesis of Mycobacterium tuberculosis. PLoS Pathog. 5, e1000344.

(8) Van der Geize, R., Yam, K., Heuser, T., Wilbrink, M. H., Hara, H., Anderton, M. C., Sim, E., Dijkhuizen, L., Davies, J. E., Mohn, W. W., and Eltis, L. D. (2007) A gene cluster encoding cholesterol catabolism in a soil actinomycete provides insight into Mycobacterium tuberculosis survival in macrophages. Proc. Natl. Acad. Sci. U. S. A. 104 (6), 1947-52.

(9) Wipperman, M. F., Sampson, N. S., and Thomas, S. T. (2014) Pathogen roid rage: cholesterol utilization by Mycobacterium tuberculosis. Crit. Rev. Biochem. Mol. Biol. 49 (4), 269-293.

(10) Kendall, S. L., Burgess, P., Balhana, R., Withers, M., Ten Bokum, A., Lott, J. S., Gao, C., Uhia-Castro, I., and Stoker, N. G. (2010) Cholesterol utilization in mycobacteria is controlled by two TetR-type transcriptional regulators: $k s t R$ and kstR2. Microbiology 156 (Pt 5), 1362-71.

(11) Kendall, S. L., Withers, M., Soffair, C. N., Moreland, N. J., Gurcha, S., Sidders, B., Frita, R., Ten Bokum, A., Besra, G. S., Lott, J. S., and Stoker, N. G. (2007) A highly conserved transcriptional repressor controls a large regulon involved in lipid degradation in Mycobacterium smegmatis and Mycobacterium tuberculosis. Mol. Microbiol. 65 (3), 684-99.

(12) Garcia-Fernandez, E., Medrano, F. J., Galan, B., and Garcia, J. L. (2014) Deciphering the transcriptional regulation of cholesterol catabolic pathway in mycobacteria: identification of the inducer of KstR repressor. J. Biol. Chem. 289 (25), 17576-88.

(13) Crowe, A. M., Stogios, P. J., Casabon, I., Evdokimova, E., Savchenko, A., and Eltis, L. D. (2015) Structural and functional characterization of a ketosteroid transcriptional regulator of Mycobacterium tuberculosis. J. Biol. Chem. 290 (2), 872-82.

(14) Yuan, T., and Sampson, N. S. (2018) Hit generation in TB drug discovery: from genome to granuloma. Chem. Rev. 118 (4), 18871916.

(15) Frye, S. V. (2006) Discovery and clinical development of dutasteride, a potent dual Salpha-reductase inhibitor. Curr. Top. Med. Chem. 6 (5), 405-21. 
(16) Frye, S. V., Haffner, C. D., Maloney, P. R., Hiner, R. N., Dorsey, G. F., Noe, R. A., Unwalla, R. J., Batchelor, K. W., Bramson, H. N., Stuart, J. D., Schweiker, S. L., van Arnold, J., Bickett, D. M., Moss, M. L., Tian, G., Lee, F. W., Tippin, T. K., James, M. K., Grizzle, M. K., Long, J. E., and Croom, D. K. (1995) Structure-activity relationships for inhibition of type 1 and 2 human 5 alpha-reductase and human adrenal 3 beta-hydroxy-delta 5-steroid dehydrogenase/3-keto-delta 5steroid isomerase by 6-azaandrost-4-en-3-ones: optimization of the C17 substituent. J. Med. Chem. 38 (14), 2621-7.

(17) Frye, S. V., Haffner, C. D., Maloney, P. R., Mook, R. A., Jr., Dorsey, G. F., Jr., Hiner, R. N., Batchelor, K. W., Bramson, H. N., Stuart, J. D., Schweiker, S. L., van Arnold, J., Bickett, D. M., Moss, M. L., Tian, G., Unwalla, R. J., Lee, F. W., Tippin, T. K., James, M. K., Grizzle, M. K., Long, J. E., and Schuster, S. V. (1993) 6-Azasteroids: potent dual inhibitors of human type 1 and 2 steroid 5 alphareductase. J. Med. Chem. 36 (26), 4313-4315.

(18) Frye, S. V., Haffner, C. D., Maloney, P. R., Mook, R. A., Jr., Dorsey, G. F., Jr., Hiner, R. N., Cribbs, C. M., Wheeler, T. N., Ray, J. A., Andrews, R. C., Batcheor, K. W., Bramson, H. N., Stuart, J. D., Schweiker, S. L., van Arnold, J., Croom, S., Bickett, D. M., Moss, M. L., Tian, G., Unwalla, R. J., Lee, F. W., Tippin, T. K., James, M. K., Grizzle, M. K., Long, J. E., and Schuster, S. V. (1994) 6-Azasteroids: structure-activity relationships for inhibition of type 1 and 2 human 5 alpha-reductase and human adrenal 3 beta-hydroxy-delta 5 -steroid dehydrogenase/3-keto-delta 5-steroid isomerase. J. Med. Chem. 37 (15), 2352-2360

(19) Thomas, S. T., Yang, X., and Sampson, N. S. (2011) Inhibition of the $M$. tuberculosis 3beta-hydroxysteroid dehydrogenase by azasteroids. Bioorg. Med. Chem. Lett. 21 (8), 2216-9.

(20) Yang, X., Gao, J., Smith, I., Dubnau, E., and Sampson, N. S. (2011) Cholesterol is not an essential source of nutrition for Mycobacterium tuberculosis during infection. J. Bacteriol. 193 (6), 1473-6.

(21) Yang, X., Dubnau, E., Smith, I., and Sampson, N. S. (2007) Rv1106c from Mycobacterium tuberculosis is a $3 \beta$-hydroxysteroid dehydrogenase. Biochemistry 46 (31), 9058-67.

(22) Wipperman, M. F., Yang, M., Thomas, S. T., and Sampson, N. S. (2013) Shrinking the FadE proteome of Mycobacterium tuberculosis: insights into cholesterol metabolism through identification of an $\alpha_{2} \beta_{2}$ heterotetrameric acyl coenzyme A dehydrogenase family. J. Bacteriol. 195 (19), 4331-4341.

(23) El-Etr, S. H., Subbian, S., Cirillo, S. L., and Cirillo, J. D. (2004) Identification of two Mycobacterium marinum loci that affect interactions with macrophages. Infect. Immun. 72 (12), 6902-13.

(24) Subbian, S., Mehta, P. K., Cirillo, S. L., and Cirillo, J. D. (2007) The Mycobacterium marinum mel2 locus displays similarity to bacterial bioluminescence systems and plays a role in defense against reactive oxygen and nitrogen species. BMC Microbiol. 7, 4.

(25) Janagama, H. K., Tounkang, S., Cirillo, S. L., Zinniel, D. K., Barletta, R. G., and Cirillo, J. D. (2013) Molecular analysis of the Mycobacterium tuberculosis lux-like mel2 operon. Tuberculosis 93 (Suppl), S83-7.

(26) Santangelo, M. P., Blanco, F. C., Bianco, M. V., Klepp, L. I., Zabal, O., Cataldi, A. A., and Bigi, F. (2008) Study of the role of Mce3R on the transcription of mce genes of Mycobacterium tuberculosis. BMC Microbiol. 8, 38.

(27) de la Paz Santangelo, M., Klepp, L., Nunez-Garcia, J., Blanco, F. C., Soria, M., Garcia-Pelayo, M. C., Bianco, M. V., Cataldi, A. A., Golby, P., Jackson, M., Gordon, S. V., and Bigi, F. (2009) Mce3R, a TetR-type transcriptional repressor, controls the expression of a regulon involved in lipid metabolism in Mycobacterium tuberculosis. Microbiology 155 (Pt 7), 2245-2255.

(28) Balhana, R. J., Singla, A., Sikder, M. H., Withers, M., and Kendall, S. L. (2015) Global analyses of TetR family transcriptional regulators in mycobacteria indicates conservation across species and diversity in regulated functions. BMC Genomics 16, 479.

(29) Huitric, E., Verhasselt, P., Koul, A., Andries, K., Hoffner, S., and Andersson, D. I. (2010) Rates and mechanisms of resistance development in Mycobacterium tuberculosis to a novel diarylquinoline
ATP synthase inhibitor. Antimicrob. Agents Chemother. 54 (3), 10228.

(30) Usha, V., Gurcha, S. S., Lovering, A. L., Lloyd, A. J., Papaemmanouil, A., Reynolds, R. C., and Besra, G. S. (2011) Identification of novel diphenyl urea inhibitors of Mt-GuaB2 active against Mycobacterium tuberculosis. Microbiology 157 (Pt 1), 290-299.

(31) Bednarska, K., Kielbik, M., Sulowska, Z., Dziadek, J., and Klink, M. (2014) Cholesterol oxidase binds TLR2 and modulates functional responses of human macrophages. Mediators Inflammation 2014, 498395.

(32) Peterson, E. J., Ma, S., Sherman, D. R., and Baliga, N. S. (2016) Network analysis identifies Rv0324 and Rv0880 as regulators of bedaquiline tolerance in Mycobacterium tuberculosis. Nat. Microbiol. 1 (8), 16078.

(33) Forrellad, M. A., Klepp, L. I., Gioffre, A., Sabio y Garcia, J., Morbidoni, H. R., de la Paz Santangelo, M., Cataldi, A. A., and Bigi, F. (2013) Virulence factors of the Mycobacterium tuberculosis complex. Virulence 4 (1), 3-66.

(34) Griffin, J. W., Gawronski, J. D., DeJesus, M. A., Ioerger, T. R., Akerley, B. J., and Sassetti, C. M. (2011) High-resolution phenotypic profiling defines genes essential for mycobacterial growth and cholesterol catabolism. PLoS Pathog. 7 (9), e1002251.

(35) Cirillo, S. L., Subbian, S., Chen, B., Weisbrod, T. R., Jacobs, W. R., Jr., and Cirillo, J. D. (2009) Protection of Mycobacterium tuberculosis from reactive oxygen species conferred by the mel2 locus impacts persistence and dissemination. Infect. Immun. 77 (6), 2557-67.

(36) Saini, V., Cumming, B. M., Guidry, L., Lamprecht, D. A., Adamson, J. H., Reddy, V. P., Chinta, K. C., Mazorodze, J. H., Glasgow, J. N., Richard-Greenblatt, M., Gomez-Velasco, A., Bach, H., Av-Gay, Y., Eoh, H., Rhee, K., and Steyn, A. J. C. (2016) Ergothioneine maintains redox and bioenergetic homeostasis essential for drug susceptibility and virulence of Mycobacterium tuberculosis. Cell Rep. 14 (3), 572-585.

(37) Lin, W., de Sessions, P. F., Teoh, G. H., Mohamed, A. N., Zhu, Y. O., Koh, V. H., Ang, M. L., Dedon, P. C., Hibberd, M. L., and Alonso, S. (2016) Transcriptional profiling of Mycobacterium tuberculosis exposed to in vitro lysosomal stress. Infect. Immun. 84 (9), 2505-23.

(38) Vilchèze, C., Hartman, T., Weinrick, B., Jain, P., Weisbrod, T. R., Leung, L. W., Freundlich, J. S., and Jacobs, W. R. (2017) Enhanced respiration prevents drug tolerance and drug resistance in Mycobacterium tuberculosis. Proc. Natl. Acad. Sci. U. S. A. 114 (17), $4495-4500$.

(39) Ioerger, T. R., Feng, Y. C., Ganesula, K., Chen, X. H., Dobos, K. M., Fortune, S., Jacobs, W. R., Mizrahi, V., Parish, T., Rubin, E., Sassetti, C., and Sacchettini, J. C. (2010) Variation among genome sequences of $\mathrm{H} 37 \mathrm{Rv}$ strains of Mycobacterium tuberculosis from multiple laboratories. J. Bacteriol. 192 (14), 3645-3653.

(40) Mehra, S., Foreman, T. W., Didier, P. J., Ahsan, M. H., Hudock, T. A., Kissee, R., Golden, N. A., Gautam, U. S., Johnson, A. M., Alvarez, X., Russell-Lodrigue, K. E., Doyle, L. A., Roy, C. J., Niu, T., Blanchard, J. L., Khader, S. A., Lackner, A. A., Sherman, D. R., and Kaushal, D. (2015) The DosR regulon modulates adaptive immunity and is essential for Mycobacterium tuberculosis persistence. Am. J. Respir. Crit. Care Med. 191 (10), 1185-96.

(41) Lee, J. H., Karakousis, P. C., and Bishai, W. R. (2008) Roles of SigB and SigF in the Mycobacterium tuberculosis sigma factor network. J. Bacteriol. 190 (2), 699-707.

(42) McKinney, J. D., Honer zu Bentrup, K., Munoz-Elias, E. J., Miczak, A., Chen, B., Chan, W. T., Swenson, D., Sacchettini, J. C., Jacobs, W. R., Jr., and Russell, D. G. (2000) Persistence of Mycobacterium tuberculosis in macrophages and mice requires the glyoxylate shunt enzyme isocitrate lyase. Nature 406 (6797), 735738.

(43) Zheng, H., Colvin, C. J., Johnson, B. K., Kirchhoff, P. D., Wilson, M., Jorgensen-Muga, K., Larsen, S. D., and Abramovitch, R. B. (2017) Inhibitors of Mycobacterium tuberculosis DosRST signaling and persistence. Nat. Chem. Biol. 13 (2), 218-225. 
(44) Bruhn, D. F., Scherman, M. S., Liu, J., Scherbakov, D., Meibohm, B., Bottger, E. C., Lenaerts, A. J., and Lee, R. E. (2015) In vitro and in vivo evaluation of synergism between anti-tubercular spectinamides and non-classical tuberculosis antibiotics. Sci. Rep. 5, 13985.

(45) Ramon-Garcia, S., Ng, C., Anderson, H., Chao, J. D., Zheng, X. J., Pfeifer, T., Av-Gay, Y., Roberge, M., and Thompson, C. J. (2011) Synergistic drug combinations for tuberculosis therapy identified by a novel high-throughput screen. Antimicrob. Agents Chemother. 55 (8), 3861-3869.

(46) Blondiaux, N., Moune, M., Desroses, M., Frita, R., Flipo, M., Mathys, V., Soetaert, K., Kiass, M., Delorme, V., Djaout, K., Trebosc, V., Kemmer, C., Wintjens, R., Wohlkonig, A., Antoine, R., Huot, L., Hot, D., Coscolla, M., Feldmann, J., Gagneux, S., Locht, C., Brodin, P., Gitzinger, M., Deprez, B., Willand, N., and Baulard, A. R. (2017) Reversion of antibiotic resistance in Mycobacterium tuberculosis by spiroisoxazoline SMARt-420. Science 355 (6330), 1206-1211.

(47) Coulson, G. B., Johnson, B. K., Zheng, H. Q., Colvin, C. J., Fillinger, R. J., Haiderer, E. R., Hammer, N. D., and Abramovitch, R. B. (2017) Targeting Mycobacterium tuberculosis sensitivity to thiol stress at acidic $\mathrm{pH}$ kills the bacterium and potentiates antibiotics. Cell Chem. Biol. 24 (8), 993-1004.

(48) De Voss, J. J., Rutter, K., Schroeder, B. G., Su, H., Zhu, Y., and Barry, C. E., 3rd (2000) The salicylate-derived mycobactin siderophores of Mycobacterium tuberculosis are essential for growth in macrophages. Proc. Natl. Acad. Sci. U. S. A. 97 (3), 1252-7.

(49) Cho, S., Lee, H. S., and Franzblau, S. (2015) Microplate alamar blue assay (MABA) and low oxygen recovery assay (LORA) for Mycobacterium tuberculosis. Methods Mol. Biol. 1285, 281-92.

(50) Ioerger, T. R., O’Malley, T., Liao, R., Guinn, K. M., Hickey, M. J., Mohaideen, N., Murphy, K. C., Boshoff, H. I., Mizrahi, V., Rubin, E. J., Sassetti, C. M., Barry, C. E., 3rd, Sherman, D. R., Parish, T., and Sacchettini, J. C. (2013) Identification of new drug targets and resistance mechanisms in Mycobacterium tuberculosis. PLoS One 8 (9), e75245.

(51) Larsen, M. H., Biermann, K., Tandberg, S., Hsu, T., and Jacobs, W. R. (2007) Genetic manipulation of Mycobacterium tuberculosis. Curr. Protoc Microbiol 6 (1), 10A.2.1-10A.2.21.

(52) Chacko, K. I., Sullivan, M. J., Beckford, C., Altman, D. R., Ciferri, B., Pak, T. R., Sebra, R., Kasarskis, A., Hamula, C. L., and van Bakel, H. (2018) Genetic basis of emerging vancomycin, linezolid, and daptomycin heteroresistance in a case of persistent Enterococcus faecium bacteremia. Antimicrob. Agents Chemother. 62 (4), e0200717.

(53) Li, H., Handsaker, B., Wysoker, A., Fennell, T., Ruan, J., Homer, N., Marth, G., Abecasis, G., and Durbin, R. (2009) Genome Project Data Processing, S., The sequence alignment/map format and SAMtools. Bioinformatics 25 (16), 2078-9.

(54) Kurtz, S., Phillippy, A., Delcher, A. L., Smoot, M., Shumway, M., Antonescu, C., and Salzberg, S. L. (2004) Versatile and open software for comparing large genomes. Genome Biol. 5 (2), R12. 